\title{
BMJ Open Tobacco addiction and smoking cessation in Austrian migrants: a cross-sectional study
}

\author{
Matthias Urban, ${ }^{1}$ Otto Chris Burghuber, ${ }^{1}$ Canan Dereci, ${ }^{2}$ Masite Aydogan, ${ }^{2}$ \\ Eldin Selimovic, ${ }^{3}$ Selmir Catic, ${ }^{4}$ Georg-Christian Funk ${ }^{1}$
}

To cite: Urban M, Burghuber OC, Dereci C, et al. Tobacco addiction and smoking cessation in Austrian migrants: a cross-sectional study. BMJ Open 2015;5:e006510. doi:10.1136/bmjopen-2014006510

- Prepublication history and additional material is available. To view please visit the journal (http://dx.doi.org/ 10.1136/bmjopen-2014006510).

Received 21 September 2014 Revised 21 April 2015 Accepted 23 April 2015

\section{CrossMark}

\footnotetext{
${ }^{1}$ Department of Respiratory and Critical Care Medicine, Otto Wagner Hospital, Vienna, Austria

${ }^{2}$ Medical University of Vienna, Vienna, Austria ${ }^{3}$ SGKK-Zahnambulatorium, Mittersill, Austria

${ }^{4}$ Private dental practice, Grafenwörth, Austria

Correspondence to Dr Georg-Christian Funk; georg-christian.funk@ meduniwien.ac.at
}

\begin{abstract}
Objective: Recent observations revealed substantial differences in smoking behaviour according to individuals' migration background. However, smoking cessation strategies are rarely tailored on the basis of a migration background. We aimed to determine whether smoking behaviour and preferences for smoking cessation programmes differ between Austrian migrant smokers and Austrian smokers without a migration background.
\end{abstract}

Study design: Cross-sectional study.

Setting: Recruitment and interview were performed at public places in Vienna, Austria.

Participants: The 420 smokers included: 140 Bosnian, 140 Turkish migrant smokers of the first or second generation, as well as 140 Austrian smokers without a migration background.

Methods: We cross-sectionally assessed determinants of smoking behaviour and smoking cessation of every participant with a standardised questionnaire.

Primary outcome measure: The Fagerström Test for Nicotine Dependence.

Secondary outcome measures: Determinants of smoking behaviour, willingness to quit smoking and smoking cessation.

Results: Nicotine addiction expressed via the Fagerström score was significantly higher in smokers with a migration background versus those without (Bosnian migrant smokers 4.7 \pm 2.5 , Turkish migrant smokers 4.0 \pm 2.0 , Austrian smokers without a migration background $3.4 \pm 2.3, p<0.0001$ ). Bosnian and Turkish migrant smokers described a greater willingness to quit, but have had more previous cessation trials than Austrian smokers without a migration background, indicating an increased demand for cessation strategies in these study groups. They also participated in counselling programmes less often than Austrian smokers without a migration background. Finally, we found significant differences in preferences regarding smoking cessation programmes (ie, preferred location, service offered in another language besides German, and group rather than single counselling).

Conclusions: We found significant differences in addictive behaviour and cessation patterns between smokers with and without a migration background. Our results indicate a strong demand for adjusting cessation programmes to the cultural background.

\section{Strengths and limitations of this study}

- This study is a novelty in the field as we were the first to investigate the influence of a migration background on addictive behaviour and smoking cessation in Austrian migrant smokers, entailing potential implications on public health.

- The recruitment of smokers in public places may constitute a potential source of selection bias.

- The results may not be directly generalisable to other countries as the study was conducted exclusively in Austria.

- The cross-sectional study design represents a limitation of our data, as a longitudinal assessment would have provided further insight into trends of tobacco use. However, we aimed at prompt availability of the data to claim rapid implementation of corresponding public health interventions.

\section{INTRODUCTION}

In Austria, there are more than 2.3 million smokers over the age of 15, 1.6 million of whom smoke on a daily basis. ${ }^{1}$ The harmful effects of smoking on health are well known; however, nicotine addiction can be treated effectively with counselling and cessation methods. $^{2-6}$

Smokers with a migration background are prone to higher nicotine consumption. ${ }^{7-10} \mathrm{~A}$ Swiss health monitoring study revealed that Turkish migrants in Switzerland smoke more than does the indigenous population; male Turkish migrants had a smoking rate of $54 \%$, whereas $37 \%$ of Swiss men were considered smokers. Additionally, only one in five Swiss men smoked on a daily basis. ${ }^{11}$ Likewise, such observations were made in Germany, where the prevalence of smoking among first-generation Turkish migrants was $47 \%$ compared to $30 \%$ among the German reference population. ${ }^{12}$ Most interestingly, the authors found a significant decrease in smoker rates from first-generation to secondgeneration migrants. A study investigating 
Turkish immigrants in Germany and the Netherlands revealed recent immigration and short duration of stay in the host country as risk factors for smoking. ${ }^{13}$ In addition to cultural background and sex, there is a remarkable association between education and smoking behaviour. A Dutch study revealed a significant difference in smoking habits of male versus female Turkish migrants. Men from low socioeconomic groups and women from rather high socioeconomic classes represent the majority of heavy smokers in Amsterdam. ${ }^{14}$ Accounting for socioeconomic and sociocultural aspects as well as education therefore represents an integral part of tobacco prevention strategies. ${ }^{15}$ However, no cessation programmes tailored to the migration background have been established in Austria thus far.

Therefore, we hypothesised that smokers with a migration background in Austria may exhibit different smoking behaviours. Moreover, owing to the language barrier and cultural differences, smokers with a migration background are presumably less likely to participate in cessation programmes than smokers without a migration history. Our second hypothesis was that successful cessation strategies must be tailored to each individual's respective cultural background.

This cross-sectional study aimed to evaluate whether smoking and addictive behaviour are associated with individuals' migration background and whether smokers with a migration background participate in counselling and nicotine replacement therapy as often as smokers without a migration background. Finally, we aimed to identify specific approaches for achieving smoking cessation and characteristics for successful programmes.

\section{METHODS}

\section{Study design}

We conducted a cross-sectional study. The study sample included three groups of smokers, differentiated by their migration background. The analysis addressed parameters of addictive behaviour and the frequency of counselling and nicotine replacement therapy in Turkish or Bosnian migrant smokers versus Austrian smokers without a migration background.

\section{Recruitment}

We enrolled smokers in Vienna, Austria between winter 2011 and 2012. Independent of gender, participants were spoken to in German at public places like cafes, bus stations or mosques and asked if they smoked. To avoid selection bias, participants were not recruited from healthcare facilities or physician practices.

\section{Study sample}

The study sample included 420 participants: 140 Bosnian migrant smokers, 140 Turkish migrant smokers as well as 140 Austrian smokers without a migration background. Inclusion criteria were as follows: (1) Active smoker (defined as a person who smoked at least one cigarette per day); (2) Turkish or Bosnian migration background-following the definition of the "Recommendations for the 2010 censuses of population and housing" of the United Nations Economic Commission for Europe (UNECE), requiring that both parents were born abroad. ${ }^{16}$ Hereby, smokers who were born in other countries and raised in Austria were described as migrants of the first generation, whereas smokers born and raised in Austria were described as migrants of the second generation; (3) As participants of the reference group, active smokers without a migration background (ie, both parents were born in Austria) living primarily in Austria and having spent at least 6 months within the country; (4) At least 16 years of age. Exclusion criteria were as follows: (1) tourists; (2) smokers who did not inhale.

\section{Data collection}

Parameters of interest were collected using a standardised questionnaire which is presented in the onlineonly material ('Questionnaire'). Following a detailed oral explanation of every question, the questionnaires were handed out in the German, Turkish or Bosnian language according to the participants' migration history and were filled out under supervision of the investigators. The primary end point is the Fagerström Test for Nicotine Dependence. ${ }^{17}$ Subjects smoking at least one cigarette per day were categorised as 'smokers'.

\section{Statistical calculations and sample size estimation}

Statistical calculations were performed with the software package SPSS V.17.0 (SPSS Inc, Chicago Illinois, USA). Continuous variables with parametric distribution were described as mean and SD, and non-parametric continuous variables and ordinal variables were described as median and first and third quartiles. Categorical variables were described as frequencies and percentages. Besides descriptive data presentation via crosstabs, $\pi$ and bar charts, box plots and histograms, inferential statistics were used. Comparisons between the three groups were performed using the Kruskal-Wallis analysis of variance (ANOVA) and $\chi^{2}$ test. Post hoc comparisons were performed using the Mann-Whitney $\mathrm{U}$ test or the $\chi^{2}$ test. Correlations between variables were calculated using Kendall's coefficient. p Values less than 0.05 were accepted as statistically significant.

The sample size was estimated based on the Fagerström Test for Nicotine Dependence. ${ }^{10}$ To yield a difference of 0.5 point between the groups with an SD of 1 point, a sample size of 140 participants in each group figured out a two-sided $\alpha$ of 0.05 and a power of 0.986 .

\section{Ethics}

All of the assessed data were anonymised. Owing to the absence of interventions and anonymous data, handling the need for informed consent was waived by the ethics committee. The study was conducted in accordance with the declaration of Helsinki. ${ }^{18}$ Manuscript preparation 
and data reporting were performed according to the 'Strengthening the Reporting of Observational Studies in Epidemiology' (STROBE) statement. ${ }^{19}$

\section{RESULTS}

\section{Participant characteristics}

A total of 420 participants were available for the analysis. The sample consisted of three groups of 140 smokers each, with either a Bosnian or Turkish migration background and Austrian smokers without a migration background. Participant characteristics are depicted in table 1. The study groups were well matched in terms of age and sex. We observed significant differences in school and vocational training. Turkish migrant smokers had fewer years of schooling than Bosnian migrant smokers and Austrian smokers without a migration background.

\section{Characteristics of tobacco addiction}

The main characteristics of tobacco addiction are listed in table 2. Overall tobacco addiction, quantified by means of the 'Fagerström Test for Nicotine Dependence', showed that Bosnian migrant smokers had the highest level of dependency (4.7 \pm 2.5$)$, followed by Turkish migrant smokers $(4.0 \pm 2.5)$, whereas the lowest level of dependency was observed in the group of Austrian smokers without a migration background (3.4 \pm 2.3 ) (figure 1). We found a significant difference in the Fagerström score between male and female Bosnian migrant smokers $(5.3 \pm 2.6$ vs $4.1 \pm 2.3, \mathrm{p}=0.05)$. This observation was not found in Turkish migrant smokers $(\mathrm{p}=0.087)$ or Austrian smokers without a migration background ( $p=0.651$ ). We did not find a significant association between age and Fagerström score in one of our study groups. Univariate analysis of the entire sample indicated a significant inverse correlation between the number of years of schooling and the Fagerström score (Kendall's $\tau=-0.17, \mathrm{p}<0.001$ ). Moreover, we observed a significant association between Fagerström score and the highest level of education in the entire sample (ANOVA, $\mathrm{p}<0.001$ ) as well as in Bosnian (ANOVA, $\mathrm{p}<0.001$ ) and Turkish migrant smokers (ANOVA, $\mathrm{p}=0.032$ ), but not in Austrian smokers without a migration background (ANOVA, $\mathrm{p}=0.90$ ).

The age at which the first cigarette was smoked was comparable in all three groups. In terms of daily cigarette consumption, Bosnian migrant smokers revealed a substantially higher amount of smokers consuming more than 30 cigarettes daily compared to Turkish migrant smokers and Austrian smokers without a migration background. Trends in individual smoking behaviour were significantly different, with a tendency to increase the number of smoked cigarettes over time in $45 \%$ in Bosnian migrant smokers versus $40 \%$ in Turkish migrant smokers and only $24 \%$ in Austrian smokers without a migration background. A tendency towards decreased cigarette consumption was observed in $26 \%$ of Turkish migrant smokers, $6.4 \%$ of Bosnian migrant smokers and $19 \%$ of Austrian smokers without a migration background.

\section{Characteristics of smoking cessation}

Characteristics of smoking cessation are summarised in table 3 . Turkish migrant smokers were significantly more

Table 1 Participant characteristics

\begin{tabular}{|c|c|c|c|c|c|}
\hline & $\begin{array}{l}\text { Austrian } \\
n=140 \\
n(\%)\end{array}$ & $\begin{array}{l}\text { Bosnian } \\
n=140 \\
n(\%)\end{array}$ & $\begin{array}{l}\text { Turkish } \\
n=140 \\
n(\%)\end{array}$ & p Value & Post hoc analyses \\
\hline Age, years & $37 \pm 12$ & $39 \pm 13$ & $36 \pm 13$ & 0.12 & \\
\hline Sex, male & $66(47.1)$ & $79(56.4)$ & $75(53.6)$ & 0.28 & \\
\hline School, years & $12 \pm 2.0$ & $12 \pm 3.0$ & $10 \pm 3.0$ & $<0.001$ & $0.173^{*} ;<0.001 \dagger ;<0.001 \ddagger$ \\
\hline Highest level of education & & & & $<0.001$ & $0.558^{*} ;<0.001 \dagger ;<0.001 \ddagger$ \\
\hline Primary school & $22(15.7)$ & $26(18.6)$ & $65(46.4)$ & & \\
\hline Apprenticeship & $53(37.9)$ & $60(42.9)$ & $34(24.3)$ & & \\
\hline Matura & $52(37.1)$ & $41(29.3)$ & $41(29.3)$ & & \\
\hline University degree & $13(9.3)$ & $13(9.3)$ & 0 & & \\
\hline Employment & & & & $<0.001$ & $<0.001^{*} ;<0.001 \dagger ;<0.001 \ddagger$ \\
\hline Manual worker & $21(15.0)$ & $89(6) 3.6$ & 53 (37.9) & & \\
\hline Employee & $79(56.4)$ & $6(4.3)$ & $9(6.4)$ & & \\
\hline Managing employee & $9(6.4)$ & $7(5.0)$ & $1(0.7)$ & & \\
\hline Self-employed & $3(2.1)$ & $5(3.6)$ & $4(2.9)$ & & \\
\hline Civil servant & $4(2.9)$ & $6(4.3)$ & 0 & & \\
\hline Retiree & $2(1.4)$ & $7(5.0)$ & $9(6.4)$ & & \\
\hline Pupil/student & $12(8.6)$ & $11(7.9)$ & $26(18.6)$ & & \\
\hline Unemployed/housewife & $10(7.1)$ & $9(6.4)$ & $38(27.1)$ & & \\
\hline
\end{tabular}


Table 2 Characteristics of tobacco addiction

\begin{tabular}{|c|c|c|c|c|c|}
\hline & $\begin{array}{l}\text { Austrian } \\
\mathrm{n}=140 \\
\mathrm{n}(\%)\end{array}$ & $\begin{array}{l}\text { Bosnian } \\
n=140 \\
n(\%)\end{array}$ & $\begin{array}{l}\text { Turkish } \\
n=140 \\
n(\%)\end{array}$ & p Value & Post hoc analyses \\
\hline Age of first cigarette & $16 \pm 3.4$ & $16 \pm 3.4$ & $17 \pm 5.7$ & 0.25 & \\
\hline Daily cigarettes & & & & 0.002 & $0.018^{*} ; 0.219 \dagger ;<0.001 \ddagger$ \\
\hline $0-10$ & $40(28.6)$ & $30(21.4)$ & $54(38.6)$ & & \\
\hline $11-20$ & $64(45.7)$ & $56(40.0)$ & $59(42.1)$ & & \\
\hline $21-30$ & $29(20.7)$ & $40(28.6)$ & $15(10.7)$ & & \\
\hline 31 or more & $7(5.0)$ & $14(10.0)$ & $12(8.6)$ & & \\
\hline First cigarette after awakening (min) & & & & $<0.001$ & $<0.001^{*} ; 0.032 \dagger ; 0.102 \ddagger$ \\
\hline Within 5 & $6(4.3)$ & $26(18.6)$ & $18(12.9)$ & & \\
\hline 06-30 & $41(29.3)$ & $32(22.9)$ & $37(26.4)$ & & \\
\hline $31-60$ & $51(36.4)$ & $23(16.4)$ & $37(26.4)$ & & \\
\hline After 60 & $42(30.0)$ & $59(42.1)$ & $48(34.3)$ & & \\
\hline Smoking most in the morning & & & & $<0.001$ & $<0.001^{*} ; 0.007 \dagger ; 0.208 \ddagger$ \\
\hline Yes & $23(16.4)$ & 53 (37.9) & $43(30.7)$ & & \\
\hline No & 117 (83.6) & $87(62.1)$ & 97 (69.3) & & \\
\hline Smoking when sick/in bed & & & & 0.962 & $<0.001^{*} ;<0.001 \dagger ; 0.332 \ddagger$ \\
\hline Yes & $61(43.6)$ & $61(43.6)$ & $59(42.1)$ & & \\
\hline No & 79 (56.4) & 79 (56.4) & $81(57.9)$ & & \\
\hline Awareness of tobacco-related diseases & & & & $<0.001$ & \\
\hline Pulmonary diseases & $138(98.6)$ & $126(90.0)$ & $125(89.3)$ & 0.004 & $0.003^{*} ; 0.002 \dagger ; 0.845 \ddagger$ \\
\hline Cardiac diseases & $103(73.6)$ & $96(68.6)$ & 79 (56.4) & 0.008 & $0.429 * ; 0.004 \ddagger ; 0.036 \ddagger$ \\
\hline Vascular diseases & $114(81.4)$ & $82(58.6)$ & $73(52.1)$ & $<0.001$ & $<0.001^{*} ;<0.001 \dagger ; 0.279 \ddagger$ \\
\hline Cancer & $126(90.0)$ & $115(82.1)$ & $119(85.0)$ & 0.164 & \\
\hline Others & $24(17.1)$ & 40 (28.6) & $1(0.7)$ & $<0.001$ & \\
\hline None at all & $2(1.4)$ & $5(3.6)$ & $5(3.6)$ & 0.462 & $<0.032^{*} ;<0.001 \dagger ;<0.001 \ddagger$ \\
\hline
\end{tabular}

likely to report that they were 'definitely' willing to quit than were the Bosnian migrant smokers or Austrian smokers without a migration background (figure 2).

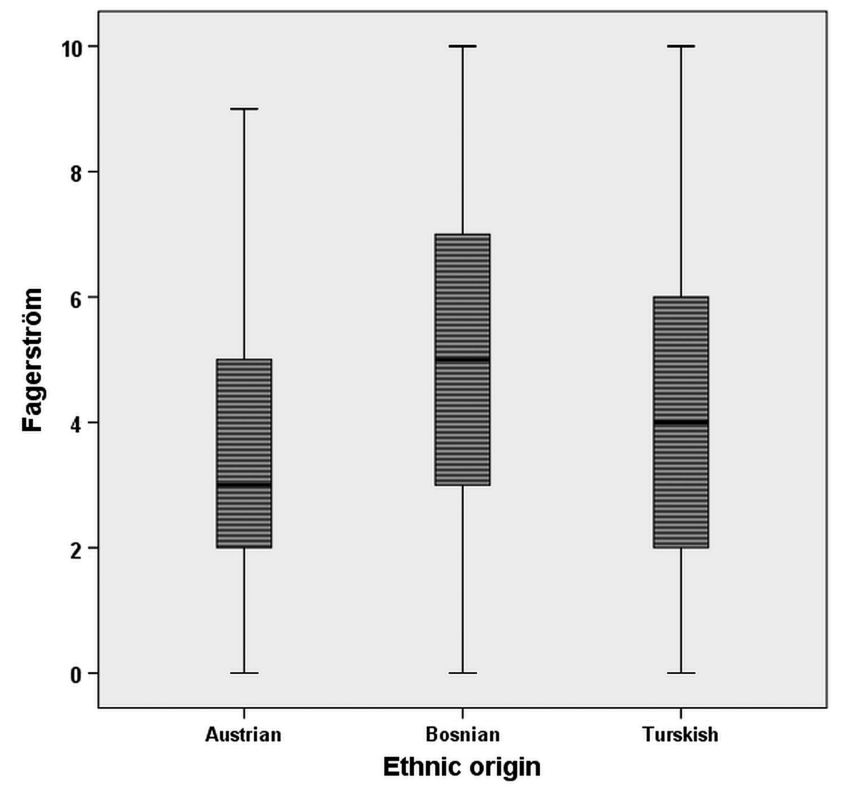

Figure 1 Mean Fagerström score of Austrian smokers without a migration background versus Bosnian and Turkish migrant smokers.
The highest percentage of smokers who already tried to quit smoking was found among Turkish migrant smokers, followed by Bosnian migrant smokers and Austrian smokers without a migration background. Turkish and Bosnian migrant smokers were also significantly more likely to have made more than two attempts to stop smoking. The highest rate of smokers who had never been offered any kind of smoking cessation until the time of assessment was found among Turkish migrants, significantly higher than Bosnian migrant smokers and Austrian smokers without a migration background (figure 3). Turkish migrant smokers were significantly more likely to prefer receiving smoking cessation support through counselling than were Bosnian migrant smokers and Austrian smokers without a migration background. Turkish migrant smokers were also more likely to choose the mosque or church as the preferred site of counselling. The most popular locations for smoking cessation were physician offices and healthcare facilities, without any observed differences among the study groups. Austrian smokers without a migration background apparently preferred single counselling, whereas Turkish migrant smokers preferred group counselling. Finally, the majority of Bosnian and Turkish migrant smokers preferred to receive smoking cessation counselling in their native language. In the group of Austrian smokers without a migration background, some chose 
Table 3 Characteristics of smoking cessation

\begin{tabular}{|c|c|c|c|c|c|}
\hline & $\begin{array}{l}\text { Austrian } \\
\mathrm{n}=140 \\
\mathrm{n}(\%)\end{array}$ & $\begin{array}{l}\text { Bosnian } \\
n=140 \\
n(\%)\end{array}$ & $\begin{array}{l}\text { Turkish } \\
\text { n=140 } \\
n(\%)\end{array}$ & p Value & Post hoc analyses \\
\hline Already tried to quit & & & & 0.024 & $0.904^{\star} ; 0.017 \dagger ; 0.023 \ddagger$ \\
\hline Yes & $81(57.9)$ & $83(59.3)$ & $101(72.1)$ & & \\
\hline No & $59(42.1)$ & $57(40.7)$ & 39 (27.9) & & \\
\hline If yes, how often & & & & 0.021 & $0.012^{*} ; 0.015 \dagger ; 0.637 \ddagger$ \\
\hline Once & $32(40.1)$ & $30(36.2)$ & $31(31.4)$ & & \\
\hline Twice & 28 (34.9) & $15(17.7)$ & $23(23.0)$ & & \\
\hline More than twice & $21(26.0)$ & $21(26.1)$ & $47(46.6)$ & & \\
\hline \multicolumn{6}{|c|}{ If yes, which cessation methods were used } \\
\hline Physician counselling & $25(30.9)$ & $33(39.8)$ & $7(6.9)$ & $<0.001$ & $0.230^{*} ;<0.001 \dagger ;<0.001 \ddagger$ \\
\hline Phone counselling & $6(7.4)$ & $7(8.4)$ & $3(3.0)$ & 0.25 & \\
\hline Group counselling & $12(14.8)$ & $10(12.0)$ & $3(3.0)$ & 0.015 & $0.600^{*} ; 0.004 \dagger ;<0.017 \ddagger$ \\
\hline Nicotine patch & $14(17.3)$ & $11(13.3)$ & $8(7.9)$ & 0.160 & \\
\hline Nicotine gum & $16(19.8)$ & $26(31.3)$ & $15(14.9)$ & 0.023 & $0.09^{*} ; 0.380 \dagger ;<0.000 \ddagger$ \\
\hline Nicotine inhalator & $12(14.8)$ & $7(8.4)$ & $16(15.8)$ & 0.300 & \\
\hline Acupuncture & $5(6.2)$ & $2(2.4)$ & $6(5.9)$ & 0.450 & \\
\hline Hypnosis & $5(6.2)$ & $1(1.2)$ & $3(3.0)$ & 0.210 & \\
\hline Book & $13(16.0)$ & $15(18.1)$ & $1(1.0)$ & $<0.001$ & $0.730^{*} ;<0.001 \dagger ;<0.001 \ddagger$ \\
\hline None at all & $36(44.4)$ & $31(37.3)$ & $68(67.3)$ & $<0.001$ & $<0.390^{*} ; 0.002 \dagger ;<0.001 \ddagger$ \\
\hline \multicolumn{6}{|l|}{ Currently preferred cessation methods } \\
\hline Counselling & $52(37.1)$ & $78(55.7)$ & $103(73.6)$ & $<0.001$ & $0.003^{*} ;<0.001 \dagger ; 0.002 \ddagger$ \\
\hline Nicotine patch & $17(12.1)$ & $28(20.0)$ & 19 (13.6) & 0.15 & \\
\hline Nicotine gum & $28(20.0)$ & $37(26.4)$ & $24(17.1)$ & 0.15 & \\
\hline Nicotine inhalator & $25(17.9)$ & $9(6.4)$ & $20(14.3)$ & 0.014 & $0.005^{\star} ;<0.516 \dagger ;<0.031 \ddagger$ \\
\hline Acupuncture & $57(40.7)$ & $15(10.7)$ & 27 (19.3) & $<0.001$ & $<0.001^{*} ;<0.001 \dagger ; 0.045 \ddagger$ \\
\hline Hypnosis & $43(30.7)$ & $17(12.1)$ & $26(18.6)$ & $<0.001$ & $<0.001^{\star} ; 0.026 \dagger ; 0.136 \ddagger$ \\
\hline Book & 18 (12.9) & $21(15.0)$ & $10(7.1)$ & 0.106 & \\
\hline Others & $26(18.6)$ & $15(10.7)$ & $11(7.9)$ & 0.019 & $0.090 * ; 0.013 \dagger ; 0.410 \ddagger$ \\
\hline \multicolumn{6}{|l|}{ Who should assist in quitting } \\
\hline Physician & $104(74.3)$ & 117 (83.6) & 109 (77.9) & 0.161 & \\
\hline Dentist & $16(11.4)$ & 36 (25.7) & $12(8.6)$ & 0.001 & $0.003^{*} ; 0.551 \dagger ;<0.001 \ddagger$ \\
\hline Medical student & $12(8.6)$ & $15(10.7)$ & $14(10.0)$ & 0.828 & \\
\hline Priest/Hodscha & $17(12.1)$ & $26(18.6)$ & $28(20.0)$ & 0.175 & \\
\hline Supervisor & 53 (37.9) & 27 (19.3) & $21(15.0)$ & $<0.001$ & $0.001^{*} ;<0.001 \dagger ;<0.341 \ddagger$ \\
\hline Others & $45(32.1)$ & $23(16.4)$ & $26(18.6)$ & 0.003 & $0.003^{*} ; 0.013 \dagger ; 0.637 \ddagger$ \\
\hline Single or group counselling preferred & & & & $<0.001$ & $0.004^{*} ;<0.001 \dagger ;<0.001 \ddagger$ \\
\hline Single counselling & $105(75.0)$ & $80(57.1)$ & $38(27.1)$ & & \\
\hline Group counselling & $35(25.0)$ & $58(41.4)$ & $102(72.9)$ & & \\
\hline No answer & 0 & $2(1.4)$ & 0 & & \\
\hline Preferred cessation language & & & & $<0.001$ & $<0.001^{*} ;<0.001 \dagger ;<0.066 \ddagger$ \\
\hline German & $100(71.4)$ & $26(18.6)$ & $31(22.1)$ & & \\
\hline Mother tongue & 40 (28.6) & 109 (77.9) & 109 (77.9) & & \\
\hline German+mother tongue & 0 & $5(3.6)$ & 0 & & \\
\hline
\end{tabular}

'German' and others chose 'mother tongue', meaning the German language as well. This misleading observation indicates the redundancy of the two possible answers in the questionnaire.

\section{DISCUSSION}

We investigated the characteristics of tobacco addiction and cessation in Bosnian and Turkish migrant smokers compared to Austrian smokers without a migration background. Our observations indicate substantial differences in addictive behaviour and in the requirements for cessation programmes in these social groups. There is a strong demand to adjust cessation programmes for migrant smokers in terms of language, counselling, cessation methods and location. The present results may serve as a basis for tailored strategies for smokers from different cultural backgrounds.

The 2006-2007 Austrian health survey revealed that the prevalence of smoking was significantly higher 


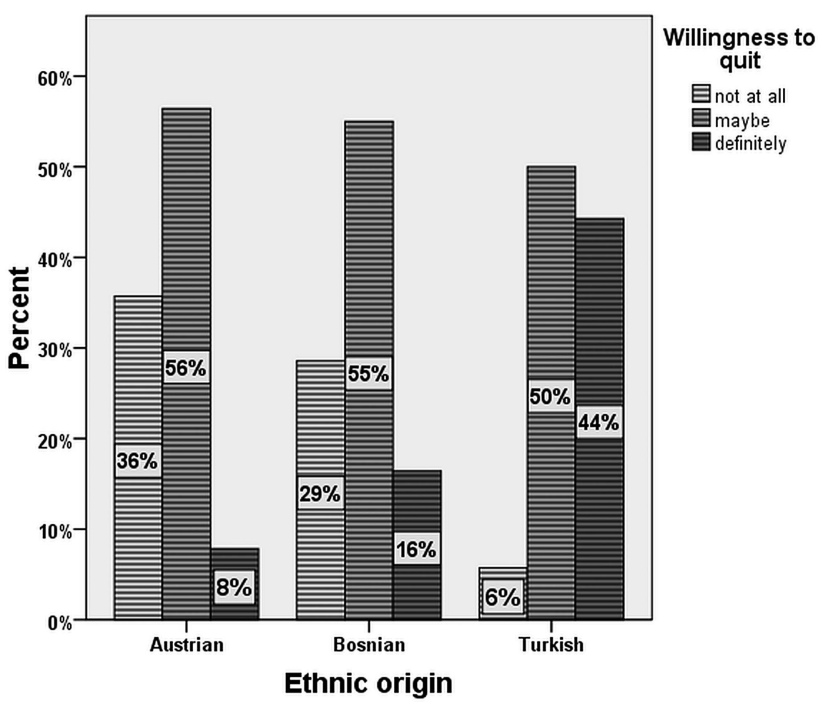

Figure 2 Willingness for smoking cessation of Austrian smokers without a migration background versus Bosnian and Turkish migrant smokers (expressed as a percentage).

among migrant smokers compared to Austrian smokers without a migration background. ${ }^{20}$ These data have been confirmed by other European studies. ${ }^{14}{ }^{21}$ A study from Switzerland showed that citizens of Turkish origin had a significantly higher rate of smokers (48\%) compared to citizens of Swiss origin $(33 \%) .{ }^{11}$ Nierkens et al ${ }^{14}$ observed that the highest prevalence of smoking in the Netherlands was among male citizens of Turkish origin $(63 \%)$, followed by Surinamese $(55 \%)$ and Moroccan $(30 \%)$ men. The authors further noted a significant inverse relation between socioeconomic status and smoking rates. A study investigating immigrants in

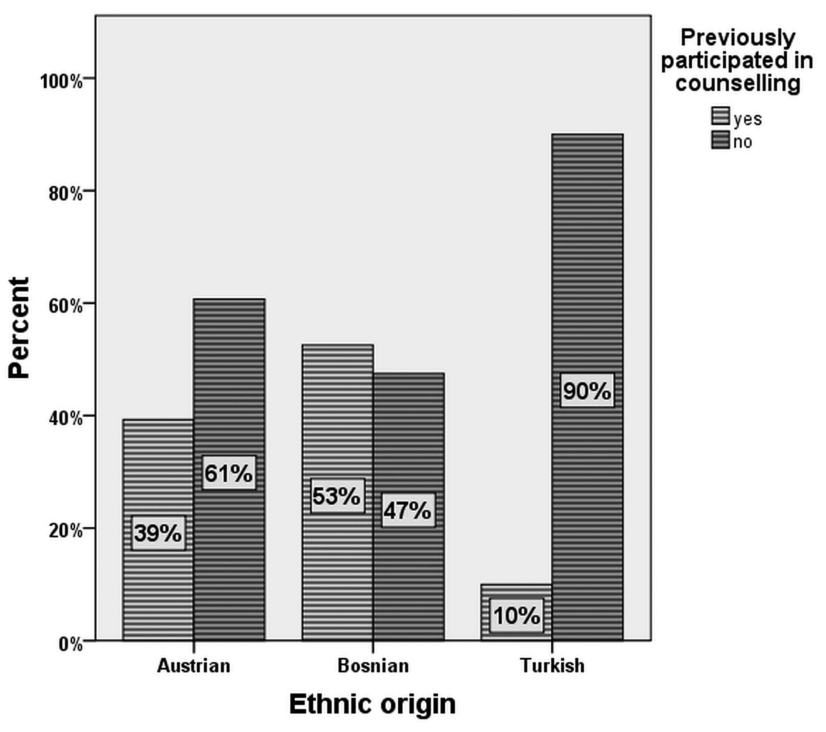

Figure 3 Percentage of Austrian smokers without a migration background versus Bosnian and Turkish migrant smokers who had previously participated in smoking cessation counselling (expressed as a percentage).
Germany as well as the Netherlands found a strong association between high smoking prevalence and recent immigration as well as short duration of stay in the host country. ${ }^{13}$ Consistent with that, we observed a highly significant difference in the Fagerström score between Turkish and Bosnian migrant smokers and Austrian smokers without a migration background. We found a significant negative correlation between completed years of schooling and the Fagerström score, indicating that a lower education level is associated with higher nicotine dependence. The relevance of these findings is strengthened by a recent study from Switzerland, where the authors found a significant association between lacking mastery of the local language and ignorance of the health effects of smoking. ${ }^{22}$

The studies mentioned above indicated the need for tailored measures for smoking prevention and cessation. In our study, we observed the highest proportion of smokers who already tried to quit among Turkish migrant smokers, followed by Bosnian migrant smokers and Austrian smokers without a migration background. Consistent with this result, the percentage of participants who categorised themselves as 'definitely' willing to quit was significantly higher in Turkish migrant smokers compared to Bosnian migrant smokers and Austrian smokers without a migration background. The recent implementation of a total ban on smoking in public places has led to an intense media discussion in Austria, indicating poor acceptance of the public health problems associated with tobacco consumption in the Austrian society. However, we did not find any Austrian data which could help in explaining this observation. The number of Turkish migrant smokers who had never been offered smoking cessation was substantially higher than the number of Austrian smokers without a migration background. So why is the subgroup of smokers with the strongest desire to quit smoking the least likely to be offered smoking cessation?

First, our data showed that $78 \%$ of both Turkish and Bosnian migrant smokers would prefer smoking counselling in their native language. Moreover, a significantly higher proportion of migrant smokers (48\% Turkish vs 28\% Bosnian migrant smokers vs 3.6\% Austrian smokers without a migration background) declared that the mosque or church was their preferred location for receiving smoking cessation counselling. Both Turkish and Bosnian migrant smokers reported a stronger preference for receiving counselling compared with Austrian smokers without a migration background, who rather tended to prefer acupuncture and hypnosis in addition to nicotine replacement products. Finally, a higher percentage of Turkish and Bosnian migrant smokers preferred group counselling rather than individual counselling.

Public health would most likely be significantly improved by offering substantially different strategies to the subgroup with the highest prevalence of smoking as well as the greatest number of attempts to quit smoking. 
In Austria, the government has not taken action so far and the existing smoking cessation programmes are designed for the general population.

We believe that our recent observations provide a compelling argument for the development of smoking cessation programmes that are tailored to the differences in addictive behaviour and counselling requirements of smokers from various cultural backgrounds. The important features of such cessation programmes would include offering individual or group counselling in the participants' native language, providing informative material and counselling in schools and mosques/ churches, recruitment via media in the respective mother tongue, predominantly visual and oral information, education about smoke-related diseases, education about nicotine replacement products and avoidance strategies, as well as regular follow-up visits to evaluate treatment progress. The limitations of our study include the fact that participants were recruited in public places, which constitutes a potential source of selection bias. Moreover, the results might not directly be generalisable to other countries as the study was conducted exclusively in Austria. The cross-sectional study design represents a limitation of our data, as a longitudinal assessment would have provided further insight into trends of tobacco use. However, we aimed at prompt availability of the data to claim rapid implementation of corresponding public health interventions.

\section{CONCLUSION}

Our study reveals substantial intercultural differences in addictive behaviours and preferences regarding cessation programmes between smokers with and without a migration background. Our findings support the need for the development of targeted strategies for smoking cessation programmes that are offered to smokers from different cultural backgrounds.

Acknowledgements G-CF thanks Ludwig Kramer who drew his attention to this rewarding field of research.

Contributors G-CF conceptualised and designed the study; CD, MA, ES and SC collected the data. G-CF, MU, CD, MA, ES and SC analysed the data; OCB, $\mathrm{G}-\mathrm{CF}, \mathrm{MU}, \mathrm{CD}, \mathrm{MA}, \mathrm{ES}$ and $\mathrm{SC}$ interpreted the data; G-CF and MU drafted the manuscript; G-CF and OCB revised the content of the draft. All authors approved the final manuscript.

Funding This research received no specific grant from any funding agency in the public, commercial or not-for-profit sectors.

\section{Competing interests None declared.}

Ethics approval The study protocol was approved by the ethics committee of the Vienna City Council (EK-Nr: 057/2012).

Provenance and peer review Not commissioned; externally peer reviewed.

Data sharing statement No additional data are available.

Open Access This is an Open Access article distributed in accordance with the Creative Commons Attribution Non Commercial (CC BY-NC 4.0) license, which permits others to distribute, remix, adapt, build upon this work noncommercially, and license their derivative works on different terms, provided the original work is properly cited and the use is non-commercial. See: http:// creativecommons.org/licenses/by-nc/4.0/

\section{REFERENCES}

1. Lichtenschopf A, Osterreichische Gesellschaft fur Pneumologie. [Guidelines for smoking cessation-update 2010]. Wiener klinische Wochenschrift 2011;123:299-315.

2. Hartmann-Boyce J, Stead LF, Cahill K, et al. Efficacy of interventions to combat tobacco addiction: Cochrane update of 2012 reviews. Addiction 2013;108:1711-21.

3. Hughes JR, Stead LF, Hartmann-Boyce J, et al. Antidepressants for smoking cessation. Cochrane Database Syst Rev 2014;(1):CD000031.

4. Stead LF, Hartmann-Boyce J, Perera R, et al. Telephone counselling for smoking cessation. Cochrane Database Syst Rev 2013;(8): CD002850.

5. Stead LF, Perera R, Bullen C, et al. Nicotine replacement therapy for smoking cessation. Cochrane Database Syst Rev 2012;(11):CD000146.

6. White AR, Rampes H, Liu JP, et al. Acupuncture and related interventions for smoking cessation. Cochrane Database Syst Rev 2014;(1):CD000009.

7. Merikangas KR, Conway KP, Swendsen J, et al. Substance use and behaviour disorders in Puerto Rican youth: a migrant family study. J Epidemiol Community Health 2009;63:310-16.

8. Ahijevych K, Bernhard L. Health-promoting behaviors of African American women. Nurs Res 1994;43:86-9.

9. Gebhardt R, Cassens S, Liecke F, et al. [Smoke-free by ramadan: experience with a low-threshold prevention offer on smoking cessation for persons with migration background]. MMW Fortschr Med 2012;154(Suppl 2):33-40.

10. Wu J, Yang T, Rockett IR, et al. Nicotine dependence among rural-urban migrants in China. BMC Public Health 2011;11:296.

11. Wie gesund sind Migrantinnen und Migranten? Die wichtigsten Ergebnisse des Gesundheitsmonitoring der schweizerischen Migrationsbevölkerung"-Bundesamt für Gesundheit—Bern. 2007 [Dec 28 2013]. http://www.alter-migration.ch/fileadmin/templates/pdf/ Wie_gesund_sind_MigrantInnen_(BAG).pdf.

12. Reeske A, Spallek J, Razum O. Changes in smoking prevalence among first- and second-generation Turkish migrants in Germanyan analysis of the 2005 Microcensus. Int J Equity Health 2009;8:26.

13. Reiss K, Sauzet O, Breckenkamp J, et al. How immigrants adapt their smoking behaviour: comparative analysis among Turkish immigrants in Germany and the Netherlands. BMC Public Health 2014; $14: 844$.

14. Nierkens V, de Vries H, Stronks K. Smoking in immigrants: do socioeconomic gradients follow the pattern expected from the tobacco epidemic? Tob Control 2006;15:385-91.

15. Salis Gross CS, Schnoz D, Cangatin S. (Nicht-)Rauchen wie ein Türke? SuchtMagazin 2009;4:30-4.

16. (UNECE) UNECE. Recommendations for the 2010 consensus of population and housing [Dec 28 2013]. http://www.unece.org/ fileadmin/DAM/stats/publications/CES_2010_Census_ Recommendations_English.pdf.

17. Heatherton TF, Kozlowski LT, Frecker RC, et al. The Fagerstrom Test for Nicotine Dependence: a revision of the Fagerstrom Tolerance Questionnaire. Br J Addict 1991;86:1119-27.

18. World Medical Association. World Medical Association Declaration of Helsinki: ethical principles for medical research involving human subjects. JAMA 2013;310:2191-4.

19. von Elm E, Altman DG, Egger M, et al. The Strengthening the Reporting of Observational Studies in Epidemiology (STROBE) statement: guidelines for reporting observational studies. Ann Intern Med 2007; 147:573-7.

20. Statistik Austria. Österreichische Gesundheitsbefragung 2006/2007 [Dec 28 2013]. http://www.statistik.at/wcm/idc/idcplg?ldcService= GET_PDF_FILE\&RevisionSelectionMethod=LatestReleased\& dDocName $=029865$

21. Schnoz D, Schaub M, Schwappach DL, et al. Developing a smoking cessation program for Turkish-speaking migrants in Switzerland: novel findings and promising effects. Nicotine Tob Res 2011;13:127-34.

22. Bodenmann P, Murith N, Favrat B, et al. Perception of the damaging effects of smoking, and brief cessation counselling by doctors. Swiss Med Wkly 2005;135:256-62. 